\title{
COMPARISON OF SELECTED PARAMETERS OF PHYSICAL ACTIVITY AT SCHOOL AND AT HOME IN CHILDREN AGED 12 IN RURAL AREAS IN POLAND
}

\author{
JAROSŁAW HERBERT ${ }^{1}$, KRZYSZTOF WARCHOŁ ${ }^{1}$, KRZYSZTOF PRZEDNOWEK ${ }^{2}$, \\ RENATA GRZYWACZ ${ }^{3}$
}

\author{
University of Rzeszów, Faculty of Physical Education, Department of Health Sciences ${ }^{1}$, \\ Department of Methodology and Computer Science ${ }^{2}$, Department of Cultural Foundations \\ of Physical Education, Tourism and Recreation², Rzeszów, Poland \\ Mailing address: Jarosław Herbert, University of Rzeszów, Faculty of Physical Education, \\ Department of Health Sciences, 3 Towarnickiego Street, 35-959 Rzeszów, tel.: +48 693522635, \\ fax: +48 17 8721861, e-mail: jherbert@ur.edu.pl
}

\begin{abstract}
Introduction. In recent years, research studies have demonstrated a significant decrease in physical activity (PA) amongst young people. Most of the young generation participate in sport and recreation too rarely, and they devote too much time to passive leisure. Diagnoses of physical activity at different stages of our lives, with particular emphasis on children and adolescents, are increasingly indicating that along with age, the level of physical activity, especially during leisure time, is decreasing. Material and methods. The aim of the study is to compare selected parameters of physical activity on a single day among students aged 12 and to determine how these parameters differ at school and at home. The study was conducted using an ActiGraph WGT3X accelerometer on a group of 100 students (50 girls and 50 boys) in a rural area of southern Poland. Results. The analysis showed that for parameters such as vigorous activity, total moderate-to-vigorous physical activity (MVPA), and step count, the observed difference between the time spent at school and outside of school was statistically significant $(\mathrm{p}<0.05)$. All of these parameters were characterised by a higher level during school time. On the basis of the analyses performed, it was concluded that the school environment contributes to increasing youth's physical activity. Effective educational programmes promoting physical activity in different forms should be addressed to youth as well as to parents (custodians), who are responsible for the physical development of their children.
\end{abstract}

Key words: accelerometer, school youth, rural area

\section{Introduction}

Research studies have shown a significant decrease in physical activity among adolescents [1]; physical activity has a tendency to decrease with age both during childhood and adolescence [1, 2]. Furthermore, inactive children can become inactive adults and thus have higher risk of complications in future life. Physical activity, health, and quality of life are closely correlated. The increasing amount of evidence confirming the health benefits of physical activity has led to a growing need to understand the health behaviour of children and adolescents and its patterns $[3,4]$.

Some authors have conducted cross-sectional studies among youth related to physical activity at and out of school [5, 6]. In many countries, physical activity at different stages of life has been investigated, with particular emphasis on children and adolescents. Such research has shown that with age, the level of physical activity, especially during leisure time, has a tendency to decrease [7].

The habit of engaging in physical activity should already be fostered at kindergartens and primary schools, and physical ed- ucation should, among others, be focused on supporting physical development. Physical education not only plays an important role in meeting pupils' physical needs starting from their early childhood, but also prepares them for life in society [8].

In physical education, an important role is fulfilled by physical activity habits which have a long-term impact on health and should be shaped during the early development of children [8]. That is why it is crucial to educate children with respect to the importance of health and leisure activities from their early childhood. If children are exposed to adverse health risks at an early age, they have a tendency to maintain this type of behaviour during puberty and adulthood, and this eventually leads to an increased risk of many chronic diseases [9].

The aim of the study is to compare selected parameters of physical activity during a single day in pupils aged 12 using a WGT3X accelerometer [10]. The day was divided into two segments: the time spent at school (from 8:00 to 14:00) and the time spent at home (from 14:00 to 20:00). Based on the review of literature, the study sought to answer the question whether there was a difference in physical activity between the time spent at school and at home. 


\section{Material and methods}

The investigation of the physical activity of 12-year-old students was carried out in Pope John Paul II School in Zarzecze, in the Podkarpackie Province in southern Poland, in December 2015. One-hundred students ( 50 girls and 50 boys) participated in the study. Participants were selected for the groups based on regular participation in school activities and the opinions of their teachers.

The research was carried out on selected days of the week (Monday and Wednesday), so that the number of hours spent at school, the number of lessons, and the amount of sports training were the same. During the tests on Monday and Wednesday, there was one obligatory lesson of physical education.

The study was carried out using new diagnostic equipment, the ActiGraph WGT3X accelerometer [10]. The use of devices such as the accelerometer is a valuable addition to questionnaire methods aimed at determining the level of physical activity.

The piezoelectric accelerometer measures sampling time, making it possible to capture the intensity, frequency, and duration of physical activity. These three dimensions of evaluation of three-axis accelerometers ( $\mathrm{Y}$ - vertical, $\mathrm{X}$ - horizontal, and $\mathrm{Z}$ - sagittal) are potentially important in the assessment of the physical activity of children and adolescents, due to the larger variety of movements performed by them as compared to adults. During the study, the accelerometer data were copied every evening into Actilife 6 software.

The parameters (variables) analysed were presented using descriptive statistical measures, that is the arithmetic mean and standard deviation. The statistical significance of differences between the two samples was verified using Student's t-test. Statistical significance was set at $\mathrm{p}<0.05$.

The analysed parameters were the following: physical activity (PA) intensity (sedentary, light, moderate, and vigorous), total moderate-to-vigorous physical activity (total MVPA), and step count (the number of steps made).

\section{Results}

Table 1 shows the basic statistics for the parameters analysed. The results for the variables are presented for two time segments during the day: the time spent at school and out of school. The analysis showed that for parameters such as vigorous PA, total MVPA, and step count, the observed difference between the time at school and outside of school was statistically significant $(\mathrm{p}<0.05)$. All these parameters were characterised by a higher average level at school, while the variability analysis showed that most of the parameters were characterised by higher volatility.

The average value of moderate-to-vigorous physical activity (MVPA) increased rapidly from 9:00 to 12:00, and then it was maintained at approximately $6 \mathrm{~min} / \mathrm{h}$. A significant fact is that with the end of the school time, this parameter decreased to approx. $3.5 \mathrm{~min} / \mathrm{h}$. Then, from 15:00 to 18:00, it remained constant and at the end of the day, it dropped to 1.5.

It is worth noting that the MVPA parameter increased only at school, where children spend most of the time in a sitting position, and it could be elevated to so-called higher spontaneous activity during breaks between lessons.

The analysis of typically sedentary activity (with intensity not exceeding 2 METs) found that the highest level (50) of this variable was recorded at the beginning of school time (9:00). Then, this value dropped for most of the time spent at school. During non-school time, there was an upward trend, with slight fluctuations between 16:00 and 20:00.

The values for sedentary activity show that the research groups sat for the longest time without breaks during the first lessons, which correlated with the results for the MVPA indicator.

The curve for the average value for light effort (intensity range from 3 to 6 METs) indicates that during the entire time at school, this parameter increased gradually, reaching its maximum at 13:00. During non-school time, there were slight fluctuations with a general downward trend. A significant fact is that the highest average level was observed around 16:00, namely during non-school time.

Figure 4 indicates that moderate activity, similarly as the MVPA indicator, rose at the beginning of the day (mainly at school) and then clearly fell (at home). The slight increase observed at approximately 4 p.m. might be related to the fact that the respondents engaged in physical training after school.

Analysing effort of very high intensity, we noted that it occurred to the greatest extent at 12:00. After 12:00, activity levels decreased, as shown in Figure 5. This indicator thus behaved

Table 1. Characteristics of parameters analysed $\left(\bar{x}\right.$ - mean, $s d$ - standard deviation, $d$ - difference between school and home, $s d_{d}-s t a n d a r d$ deviation of differences, $\mathrm{t}$ - Student's t-value, $\mathrm{p}$ - significance level)

\begin{tabular}{|c|c|c|c|c|c|c|c|c|}
\hline \multicolumn{2}{|c|}{ Variables } & $\bar{x}$ & sd & $N$ & $d$ & $s d_{d}$ & $t$ & $p$ \\
\hline \multirow{2}{*}{ Sedentary PA } & School & 41.85 & 4.51 & \multirow{2}{*}{36} & \multirow{2}{*}{1.28} & \multirow{2}{*}{13.18} & \multirow{2}{*}{0.584} & \multirow{2}{*}{0.563} \\
\hline & Home & 40.56 & 11.79 & & & & & \\
\hline \multirow{2}{*}{ Light PA } & School & 12.58 & 2.48 & \multirow{2}{*}{36} & \multirow{2}{*}{0.00} & \multirow{2}{*}{5.36} & \multirow{2}{*}{1.993} & \multirow{2}{*}{0.054} \\
\hline & Home & 12.59 & 6.24 & & & & & \\
\hline \multirow{2}{*}{ Moderate PA } & School & 2.42 & 1.12 & \multirow{2}{*}{36} & \multirow{2}{*}{0.57} & \multirow{2}{*}{1.71} & \multirow{2}{*}{0.005} & \multirow{2}{*}{0.996} \\
\hline & Home & 1.85 & 1.70 & & & & & \\
\hline \multirow{2}{*}{ Vigorous PA } & School & 1.77 & 1.40 & \multirow{2}{*}{36} & \multirow{2}{*}{0.72} & \multirow{2}{*}{1.45} & \multirow{2}{*}{2.961} & \multirow{2}{*}{0.005} \\
\hline & Home & 1.05 & 1.15 & & & & & \\
\hline \multirow{2}{*}{ Total MVPA } & School & 4.18 & 2.35 & \multirow{2}{*}{36} & \multirow{2}{*}{1.29} & \multirow{2}{*}{2.94} & \multirow{2}{*}{2.625} & \multirow{2}{*}{$0.013^{*}$} \\
\hline & Home & 2.90 & 2.75 & & & & & \\
\hline \multirow{2}{*}{ Step Count } & School & 688.71 & 261.26 & \multirow{2}{*}{36} & \multirow{2}{*}{220.69} & \multirow{2}{*}{432.30} & \multirow{2}{*}{3.063} & \multirow{2}{*}{$0.004^{x}$} \\
\hline & Home & 468.02 & 428.56 & & & & & \\
\hline
\end{tabular}


similar to MVPA, confirming that the children were the most active during their stay at school. One of the reasons for the children's inactivity at home may be the fact that they did not spend time with their peers after school.

Similarly as was the case with the vigorous activity parameter, for step count, the highest level was also noted while the children stayed at school. The most steps were performed around 12:00, and their number was about 1,000. Boys made an average of 16,000 steps during the first time segment examined in the study (8:00-14:00) and 12,000 steps in the second segment (14:00-20:00). In comparison, the girls performed an average of 8,000 steps in the first segment (8:00-14:00) and 7,100 steps in the second one (14:00-20:00).

The number of steps made after school dropped significantly, likely evidencing low physical activity taking place with family/parents.

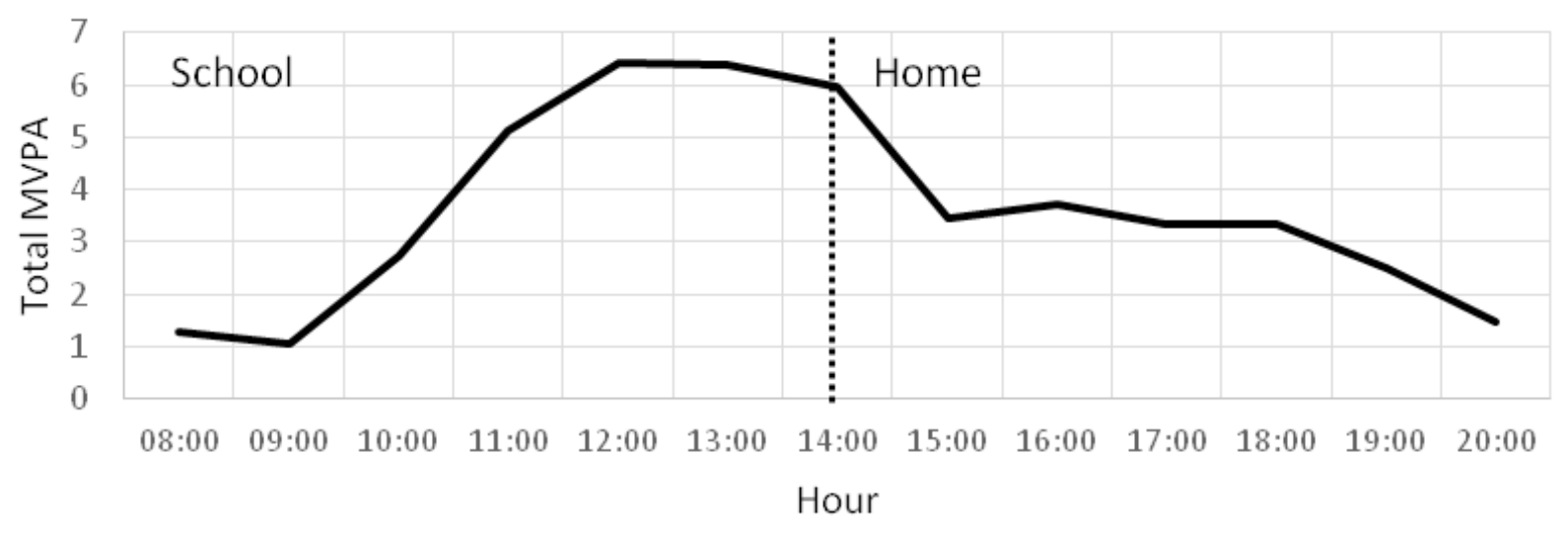

Figure 1. Level of moderate-to-vigorous physical activity (MVPA) during the period examined

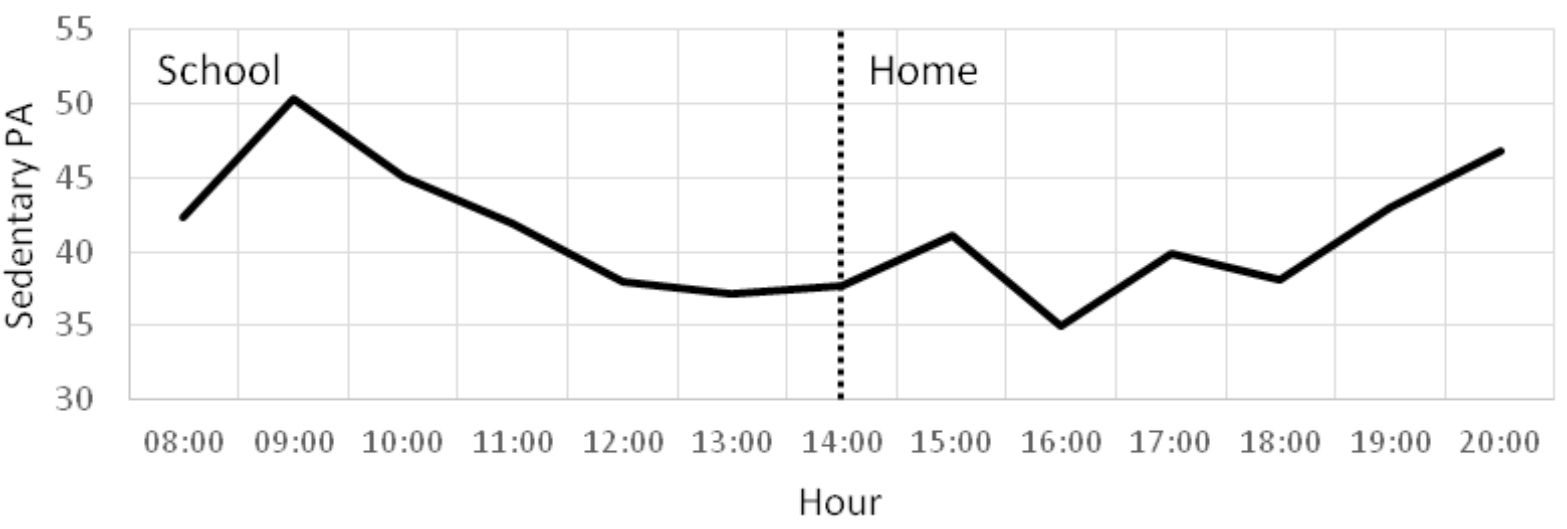

Figure 2. Level of sedentary physical activity during the period examined

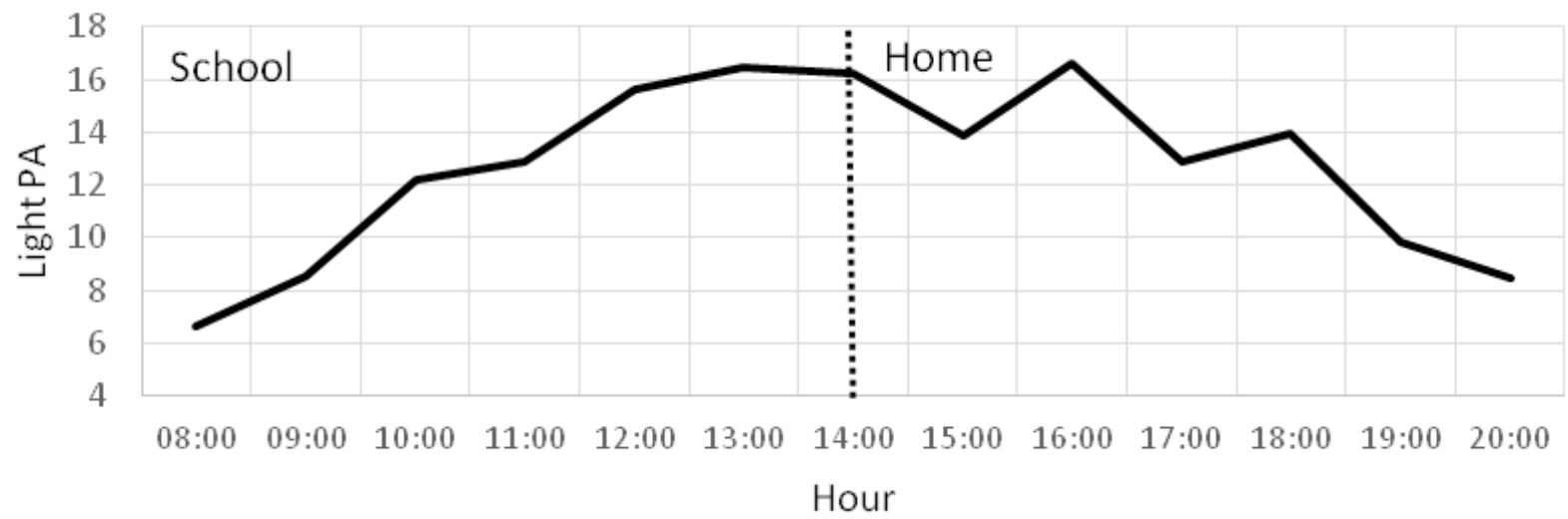

Figure 3. Level of light physical activity during the period examined 


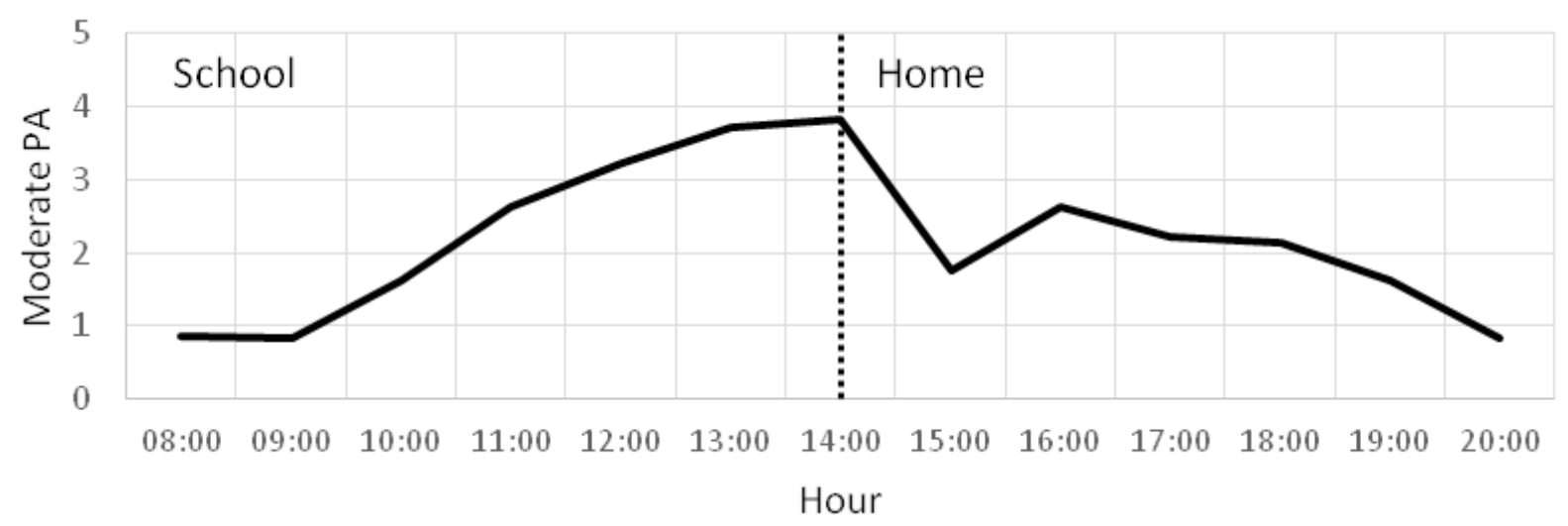

Figure 4. Level of moderate physical activity during the period examined

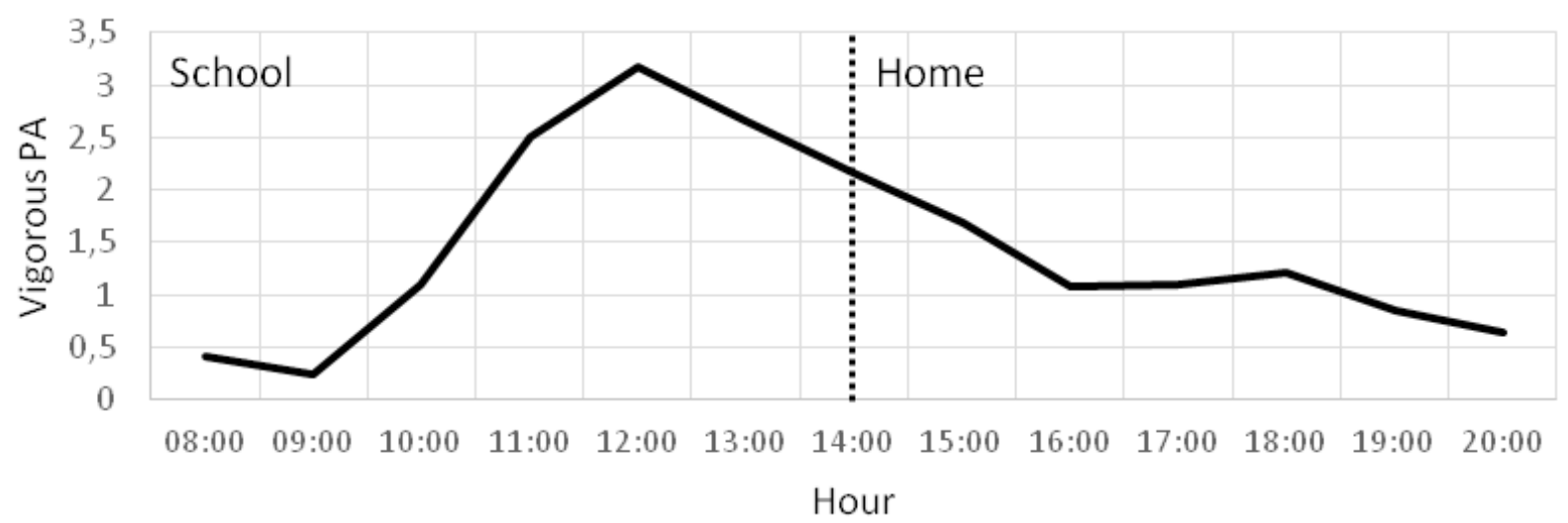

Figure 5. Level of vigorous physical activity during the period examined

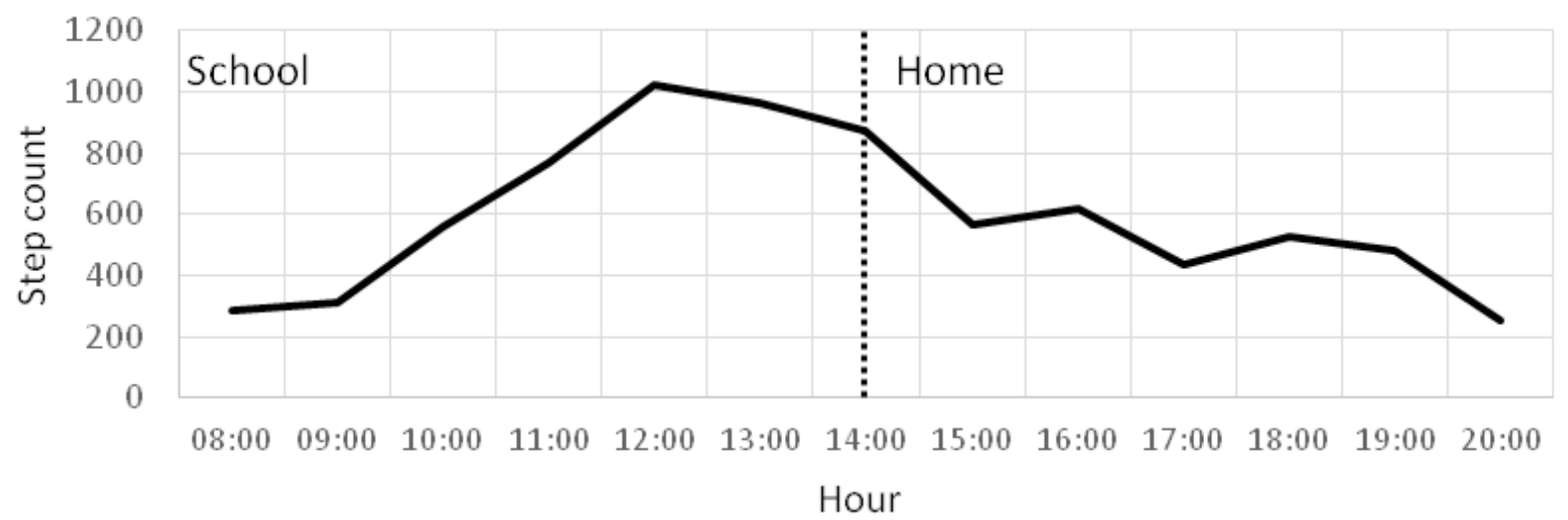

Figure 6. Step count during the period examined

\section{Discussion}

The results of the study should be used to perform efforts to promote physical activity mainly outside of school. It is recommended that children and adolescents aged 5-18 years perform moderate and intense physical activity (moderate-to-vigorous physical activity, MVPA) of a cumulative daily duration of not less than 60 minutes $[11,12,13]$.

The results of the current research are not entirely consistent and comparable with the results of studies conducted in other countries. In a study carried out in the UK on a group of 9- to 10-year-old children, higher physical activity was observed outside of school. This result may have been caused by the fact that the authors of the UK study looked at the time between 7:00 and 22:00 [14]. On the other hand, research conducted in Australia on a group of adolescents aged 12-15 years included only girls, and thus its results may have been affected by gender [15]. Some other important factors that make cross-study comparisons difficult are the use of different types of accelerometers (for example, Actigraph GTIM was applied in some research 
other than ours) and the duration of the research, which mostly lasted 7 days in other studies. For these reasons, the average values of individual parameters can vary. Summing up the above, the division of the day into segments, the duration of the study, the gender of the participants, and significantly different testing equipment can, at least partially, influence the research results. Currently, it is assumed that young people should exercise every day for at least 60 minutes, which is the equivalent of the recommended value of MVPA = 7 METs [16]. In Telford et al.'s study [17], the daily average was 4.5 during school time and slightly less during non-school time. However, in Mcmurray et al.'s research [18], the daily average value was 3.0. In Telford et al.'s study [17], overall average daily MVPA was on a similar level and amounted to 5.1 .

The sedentary activity in the research by Telford et al. [17] had an average value of 40 METs. It should be added that in that study, the respondents were aged from 8 to 12 years. However, in Carson et al.'s study [15], this value was about 35 at school and about 29 after school. In our research, there was an increase in the average amount of effort of low and moderate intensity during the time spent at school. In the research by Thompson et al. [19], there was a similar level of sedentary activity, and the average was 33. In addition, in our study, at the beginning of the time outside the classroom, there was a noticeable decrease in the average number of efforts of low intensity.

In the current study, effort of very high intensity was most often performed at school (3-3.5 METs). In comparison, in Thompson et al.'s study [19], the average was 3.5, whereas in the tests carried out by Russell et al. [20], the average was about 5.0. In the present study, there was a lower level of activity of high intensity, which was caused among others by sitting in class. The characteristic feature was that during non-school time, there were very low values of this parameter (about 1 ) indicating lower activity outside of school.

The levels of activity of moderate and high intensity (Figure 4 and 5) showed a similar trend in terms of their growth. The increase in activity started around 9:00 and continued for approximately 3.5 hours. On the other hand, these parameters decreased drastically outside of school. The decrease in the share of physical activity outside of school for children aged $11-15$ years was noticed more than a decade ago in research conducted in 9 countries of the European Union [7].

The results for step count were significantly higher than those in the studies of pre-schoolers by Vale et al. [21], where the boys performed an average of 9,225 steps per day and the girls made 9,177 steps, and by Gabel et al. [22], where an average of 8,968 steps were performed per day. In other studies involving pre-school children, this number was 7,313 steps [23] and 13,037 steps [24] a day.

In general, it is recommended that a person should make a minimum of 10,000 steps a day [25], whereas children and youth should perform 12,000 steps a day. According to TudorLocke $[6,26]$, boys should make 13,000-15,000 steps a day and girls should make 11,000-12,000 steps a day. The youth in the current study was involved mainly in very short periods of intense physical activity interspersed with low and moderate intensity.

Currently, physical activity is rarely undertaken during leisure time [27]. Diagnoses of physical activity at different stages of our lives, with particular emphasis on children and adolescents, are increasingly showing that with age, the level of physical activity, especially during leisure time, is decreasing [28]. Most young people participate in sports and recreation too rare- ly, and spend too much time engaging in passive leisure (watching TV, playing computer games, etc.) [25].

\section{Conclusions}

According to the research conducted, there is a difference in physical activity between time spent at school and at home in favour of the former. This is particularly evident in the number of steps, which significantly exceeded the level of 15,000 only when the children were at school. In addition, almost all the parameters in the study indicated that physical activity decreased after school time.

The study showed that the levels of METs and total MVPA at school and outside of school were not high, but the results in both cases were slightly higher at school.

As far as sedentary activity is concerned, an increase during school time was found at the beginning of the day, which was due to theoretical classes taking place at that time. Then the youth started to be more active, and this parameter tended to decrease. The level of moderate activity increased after school classes started and remained at a similar level (at school and outside of school) for almost the entire period of the study.

The youth performed many steps during the day, but light and vigorous activity occurred very rarely. It is worth noting that the decline in physical activity observed after school is particularly alarming.

The physical education offered by school is not able to fully meet the needs of the young body related to physical activity. However, this does not change the fact that if the amount of mandatory hours of physical education were to be reduced, this would have a negative effect on the health of children and adolescents. What is very important is appropriate motivation on the part of the physical education teacher, who should propose various forms of physical activity and approach the students individually, taking into account their interests.

The need for diagnosis and monitoring of physical activity should also be emphasised. New possibilities in this field are created by objective measurement methods using so-called motion sensors (pedometers), accelerometers, devices monitoring physiological parameters (heart rate monitors) to support the research, and questionnaires, as an alternative.

\section{Acknowledgements}

This work was funded by the Physical Education Department of Rzeszów University (UPB 507).

\section{Literature}

1. Dumith S.C., Gigante D.P., Domingues M.R., Kohl H.W. 3rd (2011). Physical activity change during adolescence: A systematic review and a pooled analysis. International Journal of Epidemiology 40, 685-698.

2. Corder K., Ogilvie D., van Sluijs E.M. (2009). Invited commentary: Physical activity over the life course: Whose behavior changes, when, and why? International Journal of Epidemiology 170, 1078-1081.

3. Guinhouya B.C., Samouda H., Zitouni D., Vilhelm C., Hubert H. (2011). Evidence of the influence of physical activity on the metabolic syndrome and/or on insulin resistance in pediatric populations: A systematic review. International Journal of Pediatric Obesity 6, 361-388.

4. Janssen I., Leblanc A.G. (2010). Systematic review of the health benefits of physical activity and fitness in school-aged 
children and youth. International Journal of Behavioral Nutrition and Physical Activity 7, 40.

5. Cox M., Schofield G., Greasley N., Kolt G.S. (2006). Pedometer steps in primary school-aged children: A comparison of school-based and out-of-school activity. Journal of Science and Medicine in Sport 9, 91-97.

6. Tudor-Locke C., Lee S.M., Morgan C.F., Beighle A., Pangrazi R.P. (2006). Children's pedometer-determined physical activity during the segmented school day. Medicine and Science in Sports and Exercise 38, 1732-1738.

7. Brettschneider W.D., Naul R. (2004). Study on young people's lifestyles and sedentariness and role of sport in the context of education and as a means of restoring the balance. Final report. Paderborn: University of Paderborn and Council of Europe Directorate-General for Education and Culture, Unit Sport.

8. Pańczyk W. (2012). Physical education for health. Rzeszów: Wyd. Uniwersytet Rzeszowski. [in Polish]

9. World Health Organization. (2005). WHO STEPS Surveillance Manual: The WHO STEPwis approach to chronic disease risk factor surveillance. Geneva: WHO Press.

10. GT3X+ and WGT3X+ Device Manual. (2014). The ActiGraph, Pensacola.

11. Department of Health and Aging. (2005). Australia's Physical Activity Recommendations for Children and Young People. Canberra: Australian Government, Department of Health and Aging.

12. United States Department of Health and Human Services. (2005). Dietary Guidelines for Americans. Washington: United States Department of Health and Human Services.

13. World Health Organization. (2010). Global recommendations on physical activity for health. Geneva: WHO Press.

14. Steele R.M., Van Sluijs E.M., Sharp S.J., Landsbaugh J.R., Ekelund U., Griffin S.J. (2010). An investigation of patterns of children's sedentary and vigorous physical activity throughout the week. International Journal of Behavioral Nutrition and Physical Activity 7, 88.

15. Carson V., Cliff D.P., Janssen X., Okely A.D. (2013). Longitudinal levels and bouts of sedentary time among adolescent girls. BMC Pediatrics 13, 173.

16. Ścibor M., Góra A. (2012). Impact of life style on body weight in adolescents on the basis of questionnaire findings in a selected group of youth from rural and urban areas. Environmental Medicine 15(1). [in Polish]

17. Telford R.M., Telford R.D., Cunningham R.B., Cochrane T., Davey R., Waddington G. (2013). Longitudinal patterns of physical activity in children aged 8 to 12 years: The LOOK study. International Journal of Behavioral Nutrition and Physical Activity 10, 81.

18. Mcmurray R.G., Ring K.B., Treuth M.S., Welk G.J., Pate R.R., Schmitz K.H. et al. (2004). Comparison of two approaches to structured physical activity surveys for adolescents. Medicine and Science in Sports and Exercise 36(12), 2135-2143.

19. Thompson A.M., McHugh T.L., Blanchard C., Campagna P.D., Durant M., Murphy R.J.L. et al. (2009). Physical activity of children and youth in Nova Scotia from 2001/02 and 2005/06. Preventive Medicine 5, 407-409.

20. Russell R.P., Stevens J., Pratt C., Sallis J.F., Schmitz K.H., Webber L.S. et al. (2006). Objectively measured physical activity in sixth-grade girls. Archives of Pediatrics and Adolescent Medicine 160(12), 1262-1268.

21. Vale S., Trost S.G., Duncan M.J., Mota J. (2015). Step based physical activity guidelines for preschool-aged children. Preventive Medicine 70, 78-82.

22. Gabel L.A., Proudfoot N.A., Obeid J., MacDonald M.J., Bray S.R., Cairney J. et al. (2012). Step count targets corresponding to new physical activity guidelines for the early years. Medicine and Science in Sports and Exercise 45, 314-8.

23. Pagels P., Boldemann C., Raustorp A. (2011). Comparison of pedometer and accelerometer measures of physical activity during preschool time on 3-to 5-year-old children. Acta Pediatric 100, 116-20.

24. Tanaka C., Tanaka S. (2009). Daily physical activity in Japanese preschool children evaluated by triaxial accelerometry: The relationship between period of engagement in moderate-to-vigorous physical activity and daily step counts. Journal of Physiological Anthropology 28, 283-8.

25. Hills A.P., Mokhtar N., Byrne N.M. (2014). Assessment of physical activity and energy expenditure: An overview of objective measures. Frontiers in Nutrition 1, 5.

26. Tudor-Locke C., Craig C.L., Aoyagi Y., Bell R.C., Croteau K.A., Bourdeaudhuij I.D. et al. (2011). How many steps/day are enough? For adults. International Journal of Behavioral Nutrition and Physical Activity 8, 78.

27. Sallis J.F., Owen N. (1999). Physical activity and behavioral medicine. Sage Publications, Thousand Oaks.

28. Dale D., Corbin C.B., Dale K.S. (2000). Restricting opportunities to be active during school time: Do children compensate by increasing physical activity levels after school? Research Quarterly for Exercise and Sport 71(3), 240-248.

Submitted: December 22, 2017

Accepted: May 7, 2018 